\title{
Deniz Kavimleri
}

\section{Hareketinde Kuraklık}

Teorisi Sorunu

Rüştü Bora BAKRIYANIK Yüksek Lisans Öğr.

Gazi Üniversitesi, SBF, Eskiçağ Tarihi, Yüksek Lisans Öğrencisi borabakriyanik@gmail.com

\section{The Problem of Drought Theory in Movement of Sea People}

\section{ÖZET}

Eskiçağ Tarihi araştırmacılarının uzun yıllardır üzerine eğildiği konuların başında Ege Göçleri yahut Deniz Kavimleri Hareketi denilen, dönemin siyasi, ekonomik ve sosyal yapısını derinden etkileyen olaylar dizisi gelmektedir. Bu olayların sebepleri ve sonuçları üzerinde uzun yıllardır çeşitli tartışmalar süregelmekte, konuyla ilgili çalışmalar yürüten bilim insanları ortak bir noktada buluşamamaktadır. Bu görüş ayrılıklarından biri göçlerin ana sebebinin kuraklık olup olmadığı yönündedir. Bu kısa çalışma tarihi metinler, arkeolojik kantlar ve doğa bilimlerinin konu ile ilgili ortaya koydukları fikirleri ve araştırmaları bir araya toplamak ve bu şekilde kuraklık olgusunun varlığını sorgulamayı amaçlamaktadır. İlk defa Carpenter tarafından ileri sürülen kuraklık tezi zaman içerisinde ortaya çıkan yeni bilgilerle değişime uğramış olmasına karşın özünü korumaya devam etmiştir. $\mathrm{Bu}$ görüş, kuraklıktan etkilenen halkların daha önce benzeri görülmemiş bir şekilde, arkalarında büyük yıkıntılara sebebiyet vererek ilerlemeleri ve sonucunda "Karanlık Çağı" başlatmaları üzerinedir. Özellikle Drews'in son yılları etkileyen, bu ve diğer tezleri yeniden tartışmaya açan çalışmaları bu makalenin yazılmasında da etkili olmuştur. Nihayetinde geçmişten günümüze yapılan çalışmalar ve ortaya atılan fikirler birbiriyle çelişmiş, kafa karıştırıcı bir hal almıştır. Bu kısa çalışma ile ortaya çıkan bu karmaşayı bir nebze olsun gidermek amaçlanmıştır.

Anahtar Kelimeler: Ege Göçleri, Kuraklık Teorisi, Deniz Kavimleri, Geç Bronz Çağı.
“Eskiçağ toplumlarının çoğunda olduğu gibi Hitit ekonomisinin kaynağı da tarıma dayanmaktaydı. Bu nedenle kuraklık ve buna bağlı olarak kıtlığın, iddia edilen göçlere neden olduğu düşünülürse Hititlerin çöküşünü anlamak ve kuraklığın Geç Tunç Çağı'ndaki önemini saptamak adına bu devlet üzerinden konuyu incelemenin kayda değer olacağını düşünmekteyiz. . "

Eser Geçmiş̧i

12/10/2016'da başvuru alındı, 13/11/2016'da kabul edildi, 25 Aralık 2016' da yayınlandı.

Paper History

Received on 12/10/2016, Accepted on 13/11/2016, Published on 25 December 2016.

DOI:

http://dx.doi.org/10.21551/jhf.281940 


\section{ABSTRACT}

For many years, ancient history researchers have focused on Aegean Migration or Sea Peoples Movement. This movements changed political, economical and social structure of the period. There are several on-going argumentations about the causes and consequences of these events but there is no common idea between the scientists who are working on this issue. The most important disagreement about the migrations is whether the main reason of movements is drought or not. In this short study, it was aimed to compile ancient texts, arceological evidences and scientific explanations about the theory of drought, and also investigate whether the theory of drought is exist or not. The theory of drought asserted by carpenter arranged with new informations and ideas over time but it has preserved its main idea. According to the theory, people devastated unprecedentedly and entered the dark ages because of the drought. Especially, Drews's study reopened the discussion about the theory of drought and this article is inspired by the opinions of Drews. Consequently, from past to present,studies and opinions are in contradiction with each other. The main purpose of this brief study was to elucidate this complicated issue.

Keywords: Aegean Migration, The Theory of Drought, The Sea Peoples, Late Bronze Age.

\section{Giriş}

19. yüzyılın ortalarından itibaren ortaya atılan "Ege Göçleri” veya "Deniz Kavimleri" teorileri zamanla farklı görüşlerle şekillenmiş, bir kısım görüşler bir süre sonra önemini kaybederken, diğer bir kısım görüşler günümüze değin tartışılmaya devam ederek gelmiştir. Bunlar arasında en çok savunulanlar kuraklık, demirciliğin ortaya çıkışı, sistem çöküşü, ordu sistemlerindeki değişim ve depremler gibi teorilerdir. Ancak halen araştırmacılar genel kabul görecek bir sebep üzerinde fikir birliğine varamamışlar ve hatta kimi uzmanlar göçlerin varlığını kısıtlı görmüss, karanlık çağların nedeni olarak büyük bir göç olayından ziyade farklı sebeplere yönelmişlerdir. ${ }^{1}$ Makalemizde konu edeceğimiz kuraklık fikri ise karanlık çağların başlangıcında varsayılan "Ege Göçleri” veya "Deniz Kavimleri" hareketlerinin nedeni olarak görülen ve bu konuda yazıll ya da yazısız kaynaklar, ki bunlara yakıldığı yahut yandığı düşünülen şehirlerden elde edilen kalıntılar örnek gösterilebilir, üzerinden sıklıkla tartışılmış bir konudur.

Kuraklık, bir bölgede normalden az yağışın görülmesiyle toprağın nemsiz hale gelerek verimliliğini kaybetmesine verilen isimdir. ${ }^{2}$ Eskiçağ tarihi boyunca çeşitli bölgelerde kuraklık felaketinin yaşandığını, buna bağlı olarak kıtlığın ortaya çımasıyla

1 Bunlara örnek olarak Kuraklık görüşünü ortaya atan Ryhs Carpenter, Discontinuity in Greek Civilization, New York, 1968. , Demirciliğin gelişimini sebep olarak gören Gordon Childe, What Happened in History, Harmondsworth, 1942., Sistem çöküşü teorisini benimseyen Mario Liverani, "The Collapse of the Near Eastern Regional System at the End of the Bronze Age: The Case of Syria", 1987., ve A.B. Knapp, Copper Production and Divine Protection: Archaeology, Ideology and Social Complexity on Bronze Age Cyprus, Göteborg, 1986., Depremler görüşünü savunan Arthur Evans, The Palace of Minos at Knossos, Londra, 1921- 1935.

2 Kapluhan, "Türkiye'de Kuraklık ve Kuraklığın Tarıma Etkisi”, s.488. 
birlikte ayaklanmaların, göçlerin ve ölümlerin meydana geldiği görülmüştür. Örneğin I. Šuppiluliuma zamanında kuraklığa dair haberlerin yer aldığı tabletler mevcuttur. ${ }^{3}$ Ancak özellikle bu hadisenin yaşandığı zamanlarda ve bölgelerde kuraklık (diğer doğal afetlerde olduğu gibi) tam manasıyla gözlemlenebilen yahut çözülmesi için önlemler alınan bir afet değildir. Ahmet Ünal'ın aktardığına göre Hititçede kuraklık kelimesini ifade eden bir sözcük henüz saptanamamıştır. ${ }^{4}$ Eskiçağ toplumlarının genelinde olduğu gibi Hititler de bu tür felaketleri tanrılara karşı günahların sonucu olarak nitelendirmiş ve yaşanan kötü durumu bir ceza olarak görmüşlerdir. ${ }^{5}$

Eskiçağ toplumlarının çoğunda olduğu gibi Hitit ekonomisinin kaynağı da tarıma dayanmaktaydı. Bu nedenle kuraklık ve buna bağlı olarak kıtlığın, iddia edilen göçlere neden olduğu düşünülürse Hititlerin çöküşünü anlamak ve kuraklığın Geç Tunç Çağı’ndaki önemini saptamak adına bu devlet üzerinden konuyu incelemenin kayda değer olacağını düşünmekteyiz. Ayrıca bu dönem adına elimizdeki kaynakların büyük çoğunluğu Hititler ve onların vassalı konumundaki devletlerden elde edilmektedir. Yine Ege Göçlerinin sonuçları bakımından en önemli olayların başında, Hitit Devleti’nin çöküşü gelmektedir. $\mathrm{Bu}$ nedenle olayın gözlemlenebileceği ve gözlenmesi en kayda değer devlet şüphesiz Hititlerdir. Aynı zamanda Hititlerin yazılı kaynaklarının zengin olması da onları kuraklık hakkında araştırma yapılabilecek hale getirmektedir. Hiç şüphesiz bunu yaparken Ugarit Krallı̆̆ yararlanılmıştır.

Sevgi Aktüre'nin aktardığı șekliyle, Hititlerin tarım toprakları oldukça kısıtlıdır. Buna göre elde edilen ürünler, iklimden etkilendiği durumda devletin elindeki ekonomik kaynaklar zayıflar ve hatta halkın yiyecek ihtiyaçları dahi gerekli miktarları karşılayamaz. ${ }^{6}$ Ancak Rudolf Naumann'ın da aktardı̆̆ı üzere, M.Ö. 13. ve 12. yüzyılda, Hititlerde saray ve tapınak yapımına hız verildiği bir dönemdir. ${ }^{7} \mathrm{Bu}$ durum esasen akıllara bazı sorular getirebilir. Ĕger kıtlık durumu varsa, bu tapınakların yapımıyla görevli halkı sakinleştirmek ne derece mümkün olacaktır? Bilindiği gibi Hititlerde halkın yapmakla yükümlü olduğu çeşitli görevler bulunmaktaydı. Bunlar askerlik, vergi ve angarya şeklinde özetlenebilir. Angarya hizmeti devlet adına imar faaliyetleri, dini vecibeler gibi çeşitli eylemlerin halk tarafından zorunlu bir şekilde yaptırılması durumudur. ${ }^{8}$ Şüphesiz kuraklık ve kıtlık yaşayan bir ülkede bu tür faaliyetleri gerçekleştirmek halkı ayaklanmaya teşvik edebilecek sebepleri de doğurabilecek niteliktedir. Ancak elimizde buna dair bir bilgi olmadığını var sayarsak, başkent kuraklık felaketinden ya etkilenmemekteydi ya da halk hükmeden gücün etkisiyle iddia edilen kıtlığa dayanmıştı. Şüphesiz bu varsayımlar, yaşanan göçlere sebep olarak gösterilen sistem çöküşü teorisini ortaya çıkarmıştır. ${ }^{9}$

Özellikle Geç Tunç Çağının bitişi, Anadolu'daki siyasi yapının köklü bir şekilde değişmesi ve "Karanlık Çağların” başlaması konusunda "Deniz Kavimleri” veya "Ege Göçleri”

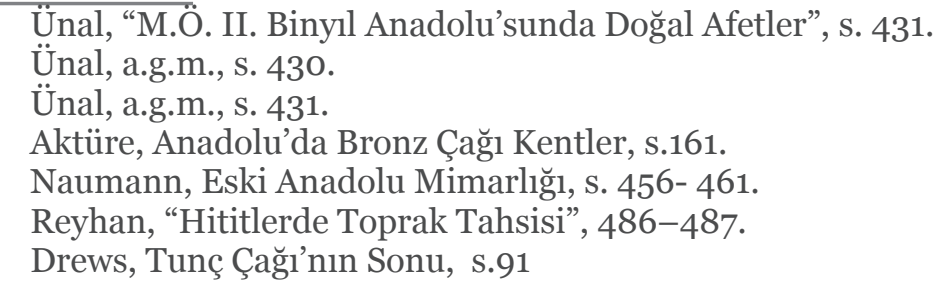


hadisesini anlamak son derece önemlidir. Bu durumda eğer bir göç meydana geldiyse bunun sebebini anlamak için ilk olarak, insanların hayat kaynağı olan besin maddelerinin Geç Tunç Çağının son evresindeki üretim miktarını saptamak gerekmektedir. Bu nedenle bu kısa çalışma içerisinde "Ege Göçleri” veya "Deniz Kavimleri” hareketine bağlı olarak ortadan kalkan şehirlerde kuraklığın etkisini ortaya koymak hedeflenmiştir. Bu amaçla yazılı kaynakların yanı sıra çeşitli arkeolojik verilerden ve doğa bilim çalışmalarından da istifade edilmiştir. Şüphesiz elimizdeki veriler geçmişe nazaran artış gösterse de zaman içerisinde yapılacak yeni çalışmalarla beraber kuraklığın varlığı ya da yokluğu üzerine daha fazla veriye ulaşmak mümkün olacaktır.

\section{Kuraklık Görüşünün Ortaya Çıkışı ve Gelişimi}

Kuraklık görüşünün ortaya çıkması Rhys Carpenter'ın 1965 senesinde Cambridge Üniversitesi'nde verdiği ve bir sene sonra basılan J.H. Gray Konferanslarındaki açıllamalarıyla olmuştur. ${ }^{10}$ Onun düşüncesine göre göçü destekleyecek fazla kanıt yoktur, buna karşın bir kuraklık ve yerli halkın buna gösterdiği reaksiyonun izleri mevcuttur. Carpenter, M.Ö. 1200 civarında Doğu Akdeniz'de kuraklığa bağlı şiddetli bir kıtlık yaşadığını ileri sürmektedir. Buna bağlı olarak insanların ağır hasar aldığını ve yaşadığı yerleri terk etmek zorunda kaldığını belirtmiş, bir sonraki adımlarının ise yiyeceğe sahip bölgelerdeki ambarları yağmalamak olduğunu vurgulamıştır. Carpenter, yangın katlarını ise bir iki kuşak sonra yağmalanan ve boşalan şehirlere düşen yıldırım sebebiyle ya da diğer doğal olaylar neticesinde gerçekleştiğini aktarmıştır. ${ }^{11}$

Carpenter'in kuraklık teorisi kısa süre içerisinde konuyla ilgilenen akademik çevrelerde ilgi görmüş ve karışıklık döneminin başlıca açıklamaları arasına girmiştir. Birçok bilim insanı kuraklık ve iklim değişimini, karışıklık döneminin sebebini ortaya koyan kesin görüss olarak benimsemiştir. ${ }^{12}$ Bunlardan biri de Kuniholm’ün Dendrokronoloji yöntemini izleyerek yaptı̆̆g çalışmadır. Buna göre kazılardan elde edilen ve M.Ö. 13. yüzyılın sonlarına tarihlenen ardıç ağacı kütüğü üzerinde bir inceleme yapılmış, sonuç olarak M.Ö. 1159 yılını takip eden 20 yıllık süre içerisinde Anadolu'nun kuraklık yaşamış olabileceği ortaya konulmuştur. ${ }^{13}$

Ancak Drews’in aktardığına göre genel kabul yalnızca Amerikan ve İngiliz bilim insanları üzerinde oluşmuşken, özellikle Avrupalı bilim insanları bu görüşe uzak kalmışlardır. ${ }^{14}$ Bu dönemin iklim olayları ile ilgili saptamalar son derece kafa karıştırıcıdır. Kimi bilim

10 Carpenter, Discontinuity in Greek Civilization, s.69., Drews, a.g.e., s.81.

11 Carpenter, a.g.e., s.69; Drews, a.g.e., s.82.

12 B. Weiss, "The Decline of Late Bronze Age Civilization as a Possible Response to Climatic Change", s.172-198; J. Neumann ve S.Parpola, "Climatic Change and the Eleventh Century Eclipse of Assyria and Babylonia”, s. 161- 182; William H. Stiebing, Jr., Out of Desert?, s. 182-187.

13 Kuniholm, "The Archaeological Record: evidence and non-evidence for climatic change", s.255. Ancak bu durum akıllara bazı soruları getirmektedir. Öncelikle belirtilen tarih göçe sebebiyet verecek tarihlerden yaklaşık bir asır sonradır. Diğer taraftan ardıç ağacı birçok bölgede yetişebilen bir ağaç olup Gordion gibi ticari yolların üzerinde bulunan bir șehire ticaret vasıtasıyla gelmiș olabilir mi? Şüphesiz bir ağaç kütüğünün ticari değeri olmayabilir fakat örnek sayısının tek olması bu dönem için kesin bir kuraklık çıkarımının yapılması için yeterli kabul edilmeyebilir.

14 Drews, a.g.e., s.82. 
insanları ${ }^{15}$ bu dönemi sıcaklık artışıyla anlatırken yine bir kısım bilim insanları dönemi sıcaklığın düştüğü bir dönem veya "küçük buz çağı" olarak nitelendirmektedir. ${ }^{16}$ Yine konuyla ilgilenen araştırmacıların bazıları ise kıtlığa neden olabilecek çapta bir kuraklık yaşanmadığını, yaşandı ise de bunun mahalli nitelikte kaldığını vurgulamışlardır. Kuniholm'ün dendrokronolojik yöntemine karşın yapılan polen çalışmaları, özellikle Kıta Yunanistan ve Türkiye'nin batı sahillerinin belirli kısımlarında belirgin değişiklikler yaşanmadığını ortaya koymuştur. ${ }^{17}$ Ancak yine farklı polen araştırmalarının gösterdiği üzere Mezopotamya'da kuraklığa dair emareler mevcuttur. Kaniewski’nin çalışmasında aktardığı üzere M.Ö 1450-1140 yılları arasında nemli hava şartları görülmektedir ve bu durumun sürekliliği söz konusudur. ${ }^{18}$ Buna karşılık yağış analizi metoduna göre yapılan çalışmalar ise farklı bir sonuç ortaya koymaktadır. Brandon L. Drake, M.Ö. 1190'larda, batı rüzgarlarının hem buharlaşmanın azalmasına neden olduğu hem de yağış miktarını etkilemesiyle, batı rüzgarlarının tatlı su mevcudiyetini azalttığını iddia etmiştir. Bu çıkarımlar Soreq Mağarasındaki yağış ölçümleri ve Voulkaria Gölü polen ölçümleriyle de desteklenmiştir. Kısacası nemliliğin, bir önceki çalışmanın aksine yüksek olmadığı aksine azalmaya başladığı ortaya konmuştur. ${ }^{19}$

Benzer klimatoloji çalışmaları bölgelere göre farklı sonuçlar vermiştir. Genç Tunç Çağının sonu ile Demir Çağı'nın başladı̆̆ı dönemde Mezopotamya, Anadolu, Arabistan, Ege Denizi, Kıta Yunanistan ve İtalya ile çevresindeki denizlerde yapılan araştırmaların bir kısmı belirgin kuraklık izlerini ortaya koyarken, ${ }^{20}$ diğer bir kısım çalışmalar bu denli kesin sonuçlar verememiştir. ${ }^{21}$ Su içerisindeki 160 veya 180 miktarını ölçerek dönem içi buharlaşmayı tespit eden çalışmalar ele aldığımız dönem için de kullanılmış ve çeşitli çıkarımlar yapmamıza katkı sağlamıştır. "Climate in the eastern Mediterranean, and adjacent regions, during the past 6000 years" adlı çalışmadan birkaç örnek vererek dönem içi buharlaşma miktarları hakkında bilgi edinebilmek mümkündür. ${ }^{22}$ Buna göre, benzer dönemler içerisinde nem-buharlaşma ilişkisine bakarak farklı miktarlar ölçümlenmiştir. ${ }^{23}$

15 Stiebing, Out of the Desert?, s.183-184.

16 Drews, a.g.e., s.83.

17 Drews, a.g.e., s.12, H.E. Wright, "Climatic Change in Mycenaean Greece”, s.125.

18 Kaniewski, "Late second-early first millennium BC abrupt climate changes in coastal Syria and their possible significance for the history of the Eastern Mediterranean", s.207-215. Buna karşın yine aynı çalışma soğumaya ve nemliliğin azalmasına giden dönemin M.Ö. 1150'den itibaren başladığını göstermektedir.

19 Drake, "The influence of climatic change on the Late Bronze Age Collapse and the Greek Dark Ages", S.1868.

20 Stiebing, Out of Desert?, s.183-184.

21 Wright, a.g.m., s.125, Shrimpton, "Regional Drought and the Economic Decline of Mycenae", s.142.

22 Finne, Holmgren, Sundqvist, Weiberg, Lindblom, s.3158. 160/180 oranının ortaya koyduğu d180 miktarı dönem içi deniz sıcaklığını göstermektedir. Kısaca aktarmak gerekirse 160 hafif oksijen izotopları manasına gelmektedir. Bu izotoplar soğuk sularda yani buharlaşmanın az olduğu denizlerde yahut okyanuslarda bulunmaktadır. Buharlaşmanın arttığı durumlarda ise 160 izotopları hafif olmaları sebebiyle havaya yükselmekte, su kaynağındaki 180 yani ağır su izotoplarının miktarı artmaktadır. Sonuç olarak bir bölgede kuraklığın varlığı sudaki 160 izotoplarının fazlalığı ile ortaya konabilmektedir.

23 Örneğin Zanchetta'nın 2007 yılında İtalya'da yaptığı oksijen izotoplarına dayalı çalışmasında M.Ö. 1400'de +2 olan değer M.Ö 1200’lere yani Geç Tunç Çağı ile Demir Çağı arasında geçiş kabul edilen döneme gelindiğinde $+1,5$ seviyelerine düşmüştür. Devam eden iki yüzyıl boyunca bu düşüş sürmüş- 
Barış Gür'ün Deniz Kavimleri adlı eserinde iklim değişikliğini desteklerken kullandığı araştırmalardan John Eddy'nin çalışması, ısı artışından çok ısı azalmasını gösterir niteliktedir. Radyokarbon testlerini temel alarak solar aktivitenin ölçüldüğü bu çalışmada M.Ö. 1420 ile 1260 tarihleri arasında güneşin dünya üzerindeki etkinliğinin düştüğü, dolayısıyla dünyadaki ortalama sıcaklıkların da azaldığı belirtilmektedir. ${ }^{24}$ Drews'in aktardığı şekliyle araştırmacılar bu durumun yağışa neden olduğunu ve ısı artışının tam aksine azalmasına sebebiyet verdiği sonucuna ulaşmışlardır. ${ }^{25}$ Bu durum kuraklık fikrinin açıklaması gereken temel bir soruyu ortaya çıarmaktadır. Kuraklığa sebep olan etken ısının artışı mı yoksa azalması mıdır?26

Kuraklık tezini savunanların bir süre sonra Carpanter'in görüşünden kopmaya başladıkları görülmektedir. Carpanter'ın, doğal yangınlar görüşünün aksine, şehirlerde yaşanılan sıkıntıların sonucunda halkın galeyana geldiği, şehirlerini ve yöneticilere ait sarayları bu nedenle yağmalayıp yaktıkları ifade edilmiştir. Ancak dönemin önemli şehirlerinden çıkarılan tabletler bu görüşü destekler nitelikte değildir. Drews'in aktardığı şekliyle Pylos ve Knossos'ta elde edilen belgeler, envanterlerin yeterli olduğunu, özellikle yiyecek sektöründe çalışan görevlilerin ise çalışmalarına devam ettiklerini göstermektedir. Yine aynı bölümde Ugarit için yeterli sayıda hayvanın bulunduğu ve çeşitli kişiler tarafından bu hayvanların yetiştirildiği belirtilmektedir. ${ }^{27} \mathrm{Bu}$ durumda halkın isyanına sebebiyet verecek bir kitlıktan söz etmek mümkün görünmemektedir. Drews'in Ugarit "fırın" tabletlerinden aktardığı fiyat tablosuna göre, kuraklık bakımından kıtlık yaşayan bir kente uygun bir değerlendirme görülmemektedir. Buna göre üç koyun ile bir elbise alınabilmektedir. Yine bir elbise ile bir öküzün değeri aynıdır. ${ }^{28}$

Yakılan bölgelerde yapılan bazı kazı sonuçlarından gıda ambarlarının da yangından şiddetle etkilendiği anlaşılmaktadır. Paul Aström'ün Midea kazısı buluntularından

tür. Yine Yunanistan'da araştırmalar yürüten Frogley ve ekibinin sonuçları M.Ö. 1400 ile M.Ö. 1000 arasında belirgin bir değişkenlik saptamamıştır. Değişken olmayan yapı M.Ö. 6oo'lere kadar devam etmiştir. Ege Denizi’nde yapılan diğer bir çalışmada ise M.Ö 1400 ile M.Ö 1000 tarihleri arasında düzenli bir şekilde düşüş gözlemlenmiştir. Türkiye'de yapılan üç çalışma ise birbirlerine göre farklı sonuçlar ortaya koymuştur. Gölhisar bölgesinde yaptıkları çalışmada Eastwood ve ekibi M.Ö 140o'lü yıllarda buharlaşmanın az olduğunu gösteren -4 değerini tespit etmişler ardından M.Ö. 1300 senelerinde bunun artışa geçerek -2 değerine çıktığını sonrasında M.Ö. 1200'e doğru önce -3 ardından -4 seviyelerine döndüğünü ortaya koymuşlardır. Buna karşılık Roberts ve ekibinin yaptığı Türkiye çalışmaları M.Ö. 1400 lerde +3 yani buharlaşmaya uygun bir yapı tespit etmişler bunun M.Ö. 130o'lerde +4 seviyesine geldiğini ardından M.Ö. 120o'e giden dönemde devamlı olarak yükselip alçaldığını ortaya koymuşlardır. Değerler bu çalışmada hiçbir zaman negatif duruma düşmemiş hatta M.Ö. 12. Asrın ilk çeyreğinde +4 'lük pozitif değere geri dönülmüştür. Fakat bunlara göre Türkiye'de yapılan en farklı çalışma Wick ve ekibi tarafından yapılanıdır. Buna göre M.Ö. 140o'lerde +0.5'e kadar düşen değerler bu tarihten itibaren M.Ö. 1000'e kadar sürekli bir biçimde artış göstermiş M.Ö. 1200'lerde +1,5 olmuş göçlerin devam ettiğinin düşünüldüğü dönemlerde de +2'lere kadar yükselmiştir.

24 Eddy, s. 961.

25 Drews, a.g.e., s. 83. Bilindiği gibi bir bölgede kuraklığın varlığı, nemlenme miktarındaki azalma yahut dengesizliklerle meydana gelebilir. Burada kast edilen soğumayla nemlenmenin azalması yahut aşırı nemlenme sonucu ekstrem yağışın bitki florasını yok ederek ekosisteme zarar vermesidir.

26 Ayrıca kimi araştırmaların iddiasına göre düşük solar aktivite depremlere sebebiyet vermiş olabilir. Ancak bu konu uzmanlar tarafından tartışılır durumdadır.

27 Palmer, "Subsistence Rations at Pylos and Knossos", s.89-124; Drews, a.g.e., s. 86

28 Drews, a.g.e., s.86.; Oren, The Sea Peoples and Their World, s.21-24.RS 18.24 
"kömürleşmiş incir, bakla ve zeytin çekirdeği kalıntıları" bu duruma örnek olarak gösterilebilir. $\mathrm{Bu}$ durumu kıtlıktan etkilenen halkların sergileyeceği bir davranış olarak yorumlamak mümkün değildir. İddia edildiği gibi yiyecek için şehirlere saldıran ve yağma eden grupların yiyecek kaynaklarını da yok etmeyi göze almaları pek mümkün görünmemektedir. ${ }^{29} \mathrm{Bu}$ çalışmadan başka Geç Tunç Çağı halklarının yiyecek alışkanlıklarına dair yapılan çalışmalar da mevcuttur. Bunlardan biri Yunanistan'da elde edilen buluntular üzerinden yapılan Petroutsa ve Manolis'in sabit izotop analizleridir. Çalışmanın sonuç kısmında aktarıldığı üzere, dönemin diet yapısı karasal hayvanların (koyun, keçi, sığır) yoğun bir şekilde tüketilmesine karşın, deniz ürünlerinin tüketilmediği (Mikenler dışında) vurgulanmaktadır. Bitkisel besinlere de genel manada bir yönelim olsa da dönem içi $\mathrm{C}_{4}$ denilen bitki tipinin ${ }^{30}$ tüketildiğine dair bir kanıt bulunamamış, genel manada $\mathrm{C}_{3}$ tipi bitkilerin ${ }^{31}$ tüketildiği görülmüsstür. ${ }^{32} \mathrm{Bu}$ bilgilerin ışığında $\mathrm{C}_{3}$ bitkilerin varlığından hareketle kuraklığın Yunanistan için ne derece etkili olduğu tartışmalıdır. C3 bitkiler yapısal olarak nemli yani kurak olmayan iklimlerde yetişebilen bitkilerdir. ${ }^{33}$

Yazılı kayıtların diğer bir kısmı ise kuraklık teorisini destekler görülse de yoruma açıktır. Özellikle Mısır Firavunu Merneptah'ın M.Ö. 1211 yılında kendi söylemiyle "Hatti ülkesini canlı tutmak için” gönderdiği tahıl, kuraklık teorisine temel oluşturan yazılı kaynaklardandır. ${ }^{34} \mathrm{Bu}$ durum ilk olarak Mısır'ın kuraklıktan etkilenmediğini, etkilendi ise de bunun etkisinin oldukça az olduğunu göstermektedir. Firavunun kendi ülkesinde bir kıtlık durumunun varlı̆̆ını görmezden gelip diğer bölgelere yardım etmesi akla yatmamaktadır. Ayrıca gördüğümüz bu tahıl yardımının ilk olmadığını söyleyebiliriz. Yine M.Ö.1270 yılında Mısır-Hitit barış antlaşmasından sonra II. Ramses’in III. Hattuşili'ye gönderdiği bir mektupta tahıl sevkiyatından söz edilmektedir. ${ }^{35}$

Barış Gür, Libya halklarının Mısır’a saldırmasında kuraklığın gerekçe olduğunu aktarmış ve ayrıca Libyalıların düzenlediği saldırıya "Anadolu'daki Kuraklıkla" boğuştuktan sonra kaçan Lukkaların da katıldığını belirtmiştir. ${ }^{36}$ Ancak yukarıda da belirttiğimiz üzere, genel bir kuraklık durumundan bahsedilen bu dönem için, Mısır'a coğrafi anlamda çok yakın durumda olan Libya kuraklıkla boğuşurken, Mısır kuraklıkla yüzleşmemiştir. Bu durumu yalnızca Nil’in bereketli deltasıyla açıklama yoluna giden araştırmacılar, kuraklığın bölgesel nitelikte kaldığını da kabul etmek durumundadır. Carpenter'ın iddia ettiği gibi Akdeniz’in tamamını etkileyen büyük kuraklık Mısır'ı etkilememiş, Mısır kendi halkını beslemenin yanı sıra Hititlere de yardım edebilmiştir. Bu durum Misır ve Mezopotamya gibi nehir çevrelerinde şekillenen bölgelerin kuraklıktan kurtulabildiğini göstermektedir. Yani bölgesel değişkenler kuraklı̆̆ın etkisini azaltabilecek niteliktedir. Bu durumda

29 Drews, a.g.e., s.87.

30 C4 bitkilere örnek olarak Darı, Süpürge Darısı ve Şeker Kamışı verilebilir. Yamori, Hikosaka, Way, "Temperature Response of Photosynthesis in $\mathrm{C}_{3}, \mathrm{C}_{4}$ and $\mathrm{CAM}$ plants: temperature acclimation and temperature adaption", s.3.

31 C3 bitkilere örnek olarak pirinç, buğday ve ıspanak gösterilebilir. Yamori, Hikosaka, Way, a.g.m., s.3.

32 Petroutsa, Manolis, "Reconstructing Late Bronze Age diet in mainland Greece using stable isotope analysis", s.619.

33 Taiz, Zeiger, Bitki Fizyolojisi, s.16o.

34 Umar, İlkçağda Türkiye Tarihi, s.141; Bryce, a.g.e., s.331.

35 KUB III 34; Ünal, "M.Ö. II. Binyll Anadolu'sunda Doğal Afetler”, s.436; Bryce, The Kingdom of The Hittites, 2005, s.322.

36 Drews, a.g.e., s.53. 
kapsayıcı bir kuraklıktan söz etmek yerine bölgesel etkileri olan bir kuraklık döneminden söz etmek mümkün olabilir. Firavun Merneptah, Libyalıların saldırmasıyla ilgili Büyük Karnak Yazıtı'nda çeşitli bilgiler aktarmış ve araştırmacılar söz konusu verilerden hareketle Libya'da kuraklığın yaşandığını ileri sürmüşlerdir. Bu ifadelerden ilki "günlerini ülkede aylak aylak dolaşarak geçiriyorlar ve karmların günlük doyurmak için savaşıyorlardı; Misır'a ağızlarma koyabilecekleri bir lokma aramak için gelmişlerdi”. ${ }^{37}$ Ancak bu söylem kuraklıkla baş eden bir halkı tasvir eden bir anlatı olarak yorumlanabileceği gibi aynı şekilde yağmacı bir kültürü tanımlama ifadesi olarak da yorumlanabilir. Firavun burada ülkelerindeki iklimsel durumundan ziyade, kişilerin yapısal olarak tüketici bir toplum hüviyetinde olduğunu vurgulamak, Mısır'ın onların tam aksine üretici ve üstün bir toplum olduğunu göstermek niyetinde olabilir..$^{38}$

Hitit Kralı III. Hattušili’nin eşi Tavananna Pudu-Hepa’nın II. Ramses’e yazdığı mektup kuraklığa delil olarak gösterilen kaynaklardan biridir. Kızının evliliği ile ilgili olan bu mektupta Tavananna Pudu-Hepa, Firavun'a "Kardeşime aşağıdaki konuyla ilgili olarak yazıyorum. Kızıma çeyiz olarak köleler, sığır ve koyun mu verecekmişim? Benim ülkemde arpa bile yok...” şeklinde seslenmektedir. ${ }^{39}$ Barış Gür'ün kitabında da yer verilen bu söylem birkaç sayfa sonra aktarılacak diğer bir örnekle çelişir durumdadır. Bu örnek Madduwataš İddianamesi adlı belgedir..$^{40}$ Buna göre Ahhiyava'lı Attarišiya'nın elinden kaçıp Hitit Kralı II. Tudhaliya'ya sığınan Madduwataš yalnızca ölümden değil, aynı zamanda açlıktan kurtulmuştur. ${ }^{41}$ Ancak metinde açlk bir şekilde görüldüğü gibi Hitit Kralı kendi ülkesinin zenginliğinden, yiyeceklerinin konuklarına bolca verilmesinden bahsetmektedir. $\mathrm{Bu}$ durum bize Hititlerin bu dönemde misafirlerine dahi bolca yardımda bulunacak kadar yiyeceğe sahip olduklarını, sınırlarındaki Ahhiyawa, iddiaya göre, kuraklıkla boğuşurken kendi durumlarının gayet iyi olduğunu göstermektedir. ${ }^{42}$

Ancak yine yazılı belgelerde verilen örnekler kraliyet ailesinin yiyecek bulmakta çektiği zorluğu ve bunun kuraklığa delalet ettiğini iddia etmektedir. Hitit Kralı tarafından Ugarit Kralı Ammurapi'ye gönderildiği iddia edilen mektup şu şekildedir "Ve yiyecek yüklü gemi, Sen Güneş'e, senin efendine onu gönderdin. Ülkende hiç yiyecek olmamasına rağmen." 43 Belgede açık bir şekilde Hitit kralına gönderilen bir yiyecek sevkiyatından

37 Breasted, Ancient Records, c. III, s.244.

38 Drews, a.g.e., s. 83. Bu saldırı sonrasında Libyalılar yanlarında kuzeyden gelen diğer paralı askerlerle beraber yenilgiye uğratılmıştır. Merneptah yazıtın devamında verdiği bilgilerle bu grupların sayısını ve yapısını ortaya koymuştur. Bu satırların bir kısmını şu şekilde aktarabiliriz. "Libya'nın sefil ve düşkün reisi, Ded'in oğlu Meryre- Şerden, Şekeleş, Ekveş, Lukka, Tereş- okçularıyla; ülkesindeki savaşçılarm ve cenk ehli adamlarm en iyilerini yanına alarak, Tehenu ülkesine saldırdı. Yanında karısını, çocuklarım ve ordugah reislerini getirmiş; Perire çayırlarındaki batı sınırına ulaşmıştı." Bkz. Drews, s. 52.

39 Beckman, Hittite Diplomatic Texts, Atlanta, s.127.

40 Belge Sandars'a göre içerik olarak 13. Yüzyıl dünyasına ait gibi görülse de yine kendisinin söylediği gibi 1514. Asırlara tarihlenmektedir. Sandars, The Sea Peoples: Warriors of the Ancient Mediterranean 12501150 B.C., s.110; Gür, Tunç Çağı'nı Sona Erdiren Halklar; Deniz Kavimleri, s.37.

41 Gür, Tunç Çağı'nı Sona Erdiren Halklar; Deniz Kavimleri, s. 38.

42 Gür, a.g.e., s.37. Barış Gür bu bilgiyi aktarırken, belgenin tarihlendirmesinin Sandars'a göre 13. Yüzyıl üslubuna uygun olduğunu belirtmiştir. Barış Gür'ün de aktardığı gibi belgenin tarihlendirmesi uzmanlar tarafindan 15. yahut 14. yüzyıl olarak yapılmaktadır. Bkz. Sandars, 1978, s.110

43 Sasson, “Canaanite Maritime involvement in the Second Millennium B.C.”, 1966, s.133. 
bahsedilmektedir. ${ }^{44}$ Hitit Kralıülkesindehiçyiyecekolmayan bir Ugarit kralından bahseder. Bu durum daha önce belirttiğimiz Ugarit tabletleriyle uyuşmamaktadır. Ugarit’te yiyecek sıkıntısının var olduğunu gösteren her hangi bir yazılı kaynak olmamasına karşın, Hitit kralının tespiti kuraklık teorisine inananlarca kuraklığın dayanağı olarak görülmüştür. Ahmet Ünal sevkiyatla ilgili yorumunda; bu cins açlık olaylarının Hititlerde sık sık yaşandığını ve bu nedenle mektubun tarihlenmesinin mümkün olmadığını belirtmiştir. ${ }^{45}$

Diğer bir yazılı kayıt ise muhtemelen Alašiya(Kıbrıs) Kralının Ugarit Kralına gönderdiği mektuptur.

"Oğlum bana yiyecek gönderdiğin zaman bolluk ve bereket benimle oldu, yine aynı şekilde bir gemi hazırla onu güçlendir ve yiyecek..."46

Önceki mektupta Hitit Kralının tabiriyle "Ülkesinde yiyecek olmayan” Ugarit şehri bu seferde Alaşiya şehrinin yardımına koşmuş ve yiyecek göndermiştir. Bu durumda Ugarit'in büyük bir kuraklıkla baş ettiğini düşünmek zordur. Burada akıllara Ugarit'in Mezopotamya üzerinden ticaret yoluyla yiyecek temin edebileceği gelmektedir. Fakat bu dönemde Asur ile Hititler arasında tarihin ilk ambargosu olarak da anılan IV. Tuthaliya'nın yaptığı ticari yasak söz konusudur. ${ }^{47}$

Ugarit’in yiyecek durumuyla ilgili bir diğer yazılı kayıt, Barış Gür’ün aktardığı haliyle şu şekildedir "Drdn/Zrdn adlı kişiden efendisine yazdığı mektup açıkça saldırıyı ve yıkımı içerir;

"Efendim habercin vardığında, ordu darmadağın oldu ve şehir yağmalandı. Yiyeceğimizin de bulunduğu harman yeri yandı ve ayrıca bağlarımı harap edildi. Şehrimiz soyup soğana çevrildi. Bunu bilebiliyor musun? Bunu bilebiliyor musun?"

Barış Gür'e göre bu durum kıtlıktan etkilenmiş halkların çektiği açlığı göstermektedir. ${ }^{48}$ Fakat mektupta açıkça görüldüğü gibi şehri yağmalayan kişiler harman yerini yani yiyecek kaynağını da yok etmişlerdir. Bu durum iddia edilen durumun tam zıttı dır. Ĕger bu gruplar kıtlıktan muzdarip ise harman yerini yakmak yerine, buradaki yiyecekleri elde edip tarım yapabilecekleri bu bölgeye yerleşmeleri daha normal değil midir?

Bunlara ek olarak, yıkılmaları kuraklığa kanıt olarak sunulan şehirlerin, bir süre sonra eski yerlerinin yakınlarında birkaç yerleşimle birleşerek yeniden toparlanmaya başladıkları görülmektedir. ${ }^{49} \mathrm{Bu}$ durum iki şekilde yorumlanabilir. Eğer bahsedildiği gibi bir genel göç hareketinden söz edilecekse, göçerler bu şehirleri yıktıktan sonra buraları

44 Benzer bir yiyecek sevkiyatından RS 20.212 no'lu tablette de bahsedilmektedir. Buna göre Hitit Kralı, Ugarit Kralından Kilikya'daki Ura'ya gönderilmek üzere 2000 ölçek tahıl ve takviye asker talep etmektedir.

Bryce, a.g.e., s. 331.

45 Ünal, a.g.m., s. 437.

46 Astour, "New Evidence on the Last Days of Ugarit", 1965, s.256.

47 Taş, Hitit Kralı IV. Tudhaliya, s.104.

48 Gür, a.g.e., s.57.

49 Drews, a.g.e., s.84. Örneğin Korakou, Aigeira, Teikhos Dymaion, Monemvasia, Asine, Perati, Lefkandi,Enkomi, Kition. Bkz. Drews, a.g.e., s. 46-47. 
yerleşim alanı olarak kullanmışlardır. Fakat bu durum kafada soru işaretleri yaratmaktadır. Ĕger bu gruplar bölgeye yerleşeceklerse var olan şehri kullanmak yerine şehri yok edip yakınlarına yeni bir yerleşim yeri kurmak için efor sarf etmeleri akla yatmamaktadır. Yine kuraklıktan kaçan grupların genel bir kuraklık yaşandığı iddia edilen Anadolu'ya yerleşmeleri mümkün görünmemektedir. Ayrıca çeşitli kazı sonuçlarının da gösterdiği üzere göçerlerin getirdiği seramik buluntuları ile yerli kültüre ait seramik buluntuları aynı dönem içerisinde görülmeye devam etmiştir. ${ }^{50}$ Bazı araştırmacılar yabancı seramiğin baskıcı Hitit yönetiminin ekonomi üzerindeki etkisinin kalkması sonucunda ticaretle bölgeye geldiği fikrini ortaya atarken yine bir takım araştırmacılar bu durumun kısıtlı göçe işaret ettiğini Anadolu'da şehirlerdeki nüfus yapısındaki değişmenin eldeki kaynaklara göre sınırlı kaldığını belirtmiştir. ${ }^{11}$

\section{Sonuç}

Uzun yıllardır bir sorun olarak varlı̆̆ını sürdüren "Deniz Kavimleri Hareketi” ya da diğer adıyla "Ege Göçleri” nin temel sebebi yukarıda da aktarıldığı gibi kimi araştırmacılar tarafından kuraklık olarak görülmüss ve bu konuda çeşitli tetkikler yapılmıştır. Fakat yukarıda belirtildiği şekliyle kuraklığın, ya bölgesel nitelikte kaldığı ya da kısa sürelerde etkili olduğu söylenebilir. Yapılan biyolojik ve radyokarbon çalışmaları kesin bir kuraklık bilgisi vermemekte, ortaya çıkan kuraklık izleri ya bölgesel nitelikte kalmakta ya da etkin tarihleri ile iddia edilen göç tarihleri uyuşmamaktadır. Fakat şunu belirtmek gerekir ki bu araştırmaların aksine kuraklık yoktur yahut göçler var ise bunun oluşmasında kuraklık tamamen etkisizdir demek mümkün değildir. Yazılı belgelerin gösterdiği şekliyle krallıklar yiyecek sıkıntısı yaşamaktadır. Ancak yaşadıkları bu sıkıntı anlaşıldığı kadarıyla komşu bölgelerden elde ettikleri takviyelerle giderilebilecek niteliktedir. Yine gösterdiğimiz gibi Hititler kuraklıktan ya da kıtlıktan yalnızca bu dönemde değil, çeşitli vesilelerle defalarca yüzleşmiş ve konu edilen döneme kadar varlıklarını sürdürebilmişlerdir. Bu durumda özellikle Hititler için kuraklık, göçlerin temel sebebi olmayıp ancak yan sebeplerden biri olarak yorumlanabilmektedir.

Diğer bölgelerde ise durum daha karmaşı gözükmektedir. Özellikle Libya'dan gelen saldırıların sebebi, Firavun Merneptah'ın anlatımına göre açlık ve gıda kaynaklarını ele geçirme arzusudur. “Onlar Mısır'a ağızlarına bir lokma koyabilmek için gelmişlerdi.” ${ }^{2}$

Fakat ne yazık ki bu durumu yalnızca tek taraflı kaynaklardan öğrenilebilmekteyiz. Dolayısıyla olayın diğer taraftan nasıl göründüğünü bilmeden yapılacak yorumlar son derece sıkıntılı olacaktır. Yine Batı Anadolu ve Kıta Yunanistan için söylenebilecek şeyler kısıtlıdır. Özellikle doğa bilimleri üzerinden yapılan çalışmalar ya yetersiz ya da birbiriyle çelişir vaziyettedir. Yazılı kaynaklardan aldığımız bilgilerden anlaşılabileceği gibi Mezopotamya yardımlarıyla Anadolu'yu destekleyebilecek durumdadır. Hititler hem

50 Erkanal, Geç Tunç Çağı'nda Limantepe, s. 99.

51 Mangaloğlu-Votruba, "Limantepe'de Geç Hellas III C Dönemi”, s.53. Limantepe'de göçü işaret eden GH IIIC seramik tipine rastlanmaktadır. Fakat bu doğrultuda pişirme kaplarının yetersizliği, yerleşimin Protogeometrik Dönem'e kesintisiz devam edişi ve yerli Anadolu gri seramiğinin de varlığını Genç Tunç Çağı sonrasında da sürdürmesi sebebiyle iddia edilen "göçün" bölgede sınırlı bir miktarda kaldığını göstermektedir.

52 Breasted, Ancient Records, c. III, s.244; Drews, a.g.e., s.83. 
askeri hem de tarımsal anlamda vassallarının desteğinden mahrum durumda değildir.

Carpanter'ın ortaya attığı şekliyle kuraklık ve ardından çıkan isyanların yarattığı karmaşa elimizdeki verilerle uyum sağlamamaktadır. Buna göre açlık çeken halkın isyan ettiğini, karşılarındaki orduları ortadan kaldırdıklarını, halkın yaşadıkları şehirleri yakarak yok ettiğini söyleyebilmek son derece güçtür. Böyle bir durum gerçekleştiyse de tüm şehirlerde meydana gelmesi pek mümkün görünmemektedir. Unutmamak gerekir ki ayaklanan halkın karşısında kendine göre askerlik ve savaş konusunda daha deneyimli ordular bulunmaktadır. Bu durumda isyanın böylesine geniş bir alanda sıkıntısız bir şekilde ilerleyip Mısır'a kadar karşısına çıkan her orduyu yok etmesi mümkün görünmemektedir.

Yazılı kaynaklar ve son dönem doğa bilim araştırmalarının verdiği sonuçlar birbirleriyle örtüşme içerisinde olmadığından göçlerin temel sebebini kuraklığa bağlamak oldukça zor görünmektedir. Şüphesiz bölgesel nitelikteki kuraklık ve beraberinde gelen kıtlı, halkı meydana gelebilecek karışıklıklara karşı duyarlı ve saldırgan hale getirmiş olabilir. Ancak bir devri bitirip yeni bir devir açtığı düşünülen "Ege Göçleri” yahut "Deniz Kavimleri” hareketinin en önemli sebebini kuraklığa bağlamak basit bir yaklaşım olacaktır. Burada diğer sebeplerle bütünleşik bölgesel nitelikli ayaklanmalar akla yatkındır. Buna göre sistemlerin zayıflaması, demir ve demirle üretilen materyallerin giderek artarak kullanılmaya başlanması, depremlerin yaşamı tehdit etmesi, denizden gelen akınların artışı ile bölgesel kuraklığın yakın dönemlerde cereyan etmesi, dönemi kaosa sürükleyen bütünleşik nedenlerdir. Bu durum, halkı saldırgan hale getireceği gibi yönetici, askeri ve ruhban sınıfın da yapısını bozabilecek niteliktedir. Bu sebepten dönem içerisinde meydana gelen karmaşayı tek bir nedene bağlamaktansa, tüm nedenleri birlikte incelemek daha doğru olacaktır. Tüm dünyayı sarsacak bir kuraklığın ve buna bağlı kıtlığın şüphesiz ki dönem halkları üzerindeki tesiri büyük olacaktır ancak bölgesel nitelikte bir kuraklık yalnızca kısıtlı alanı etkileyecektir.

\section{KAYNAKÇA}

AKTÜRE, Sevgi, Anadolu'da Bronz Çağı Kentleri, Tarih Vakfı Yurt Yayınları, 3. Baskı, İstanbul, 2004.

ASTOUR, Michael, "New Evidence on the Last Days of Ugarit", American Journal of Archaeology, 69, 1965, s.253-258.

ASTRÖM, Paul, “The Sea Peoples in Light of New Excavations”, Centre d'Etudes Chypriotes, III, 1985, s.3-17.

BECKMAN, Gary, Hittite Diplomatic Texts, Atlanta, 1996.

BRYCE, Trevor, The Kingdom of Hittites, New York, 2005.

CARPENTER, Ryse, Discontinuity in Greek Civilization, Norton, 1968.

DRAKE, Brandon, "The Influence of Climatic Change on the Late Bronze Age Collapse and 
Greek Dark Ages”, Journal of Archaeolohical Science, 39, 2012, s. 1862- 1870.

DREWS, Robert, Tunç Çağı’nın Sonu, Türkiye İş Bankası Yayınları, İstanbul, 2014.

EDDY, John, “The Sun Since The Bronze Age”, High Altitude Observatory National Center for Atmospheric Research Boulder, Colorado, 1976.

ERKANAL, Hayat, “Geç Tunç Çağı'nda Limantepe”, Batı Anadolu ve Doğu Akdeniz Geç Tunç Çağı Kültürleri Üzerine Yeni Araştırmalar, ed. A. Erkanal- Öktü, S. Günel, U. Deniz, Hacettepe Üniversitesi, Ankara 2008, s.92- 100.

FINNE, Martin, HOLMGREN, Karin, SUNDQVIST, Hanna, WEIBERG, Erika, LINDBLOM, Michael, "Climate in the eastern Mediterranean, and adjacent regions, during the past 6000 years", Journal of Archaeological Science, 38, 2011, s. 3153- 3173.

GÜR, Barış, Tunç Çă̆ı'nı Sona Erdiren Halklar; Deniz Kavimleri, Arkeoloji ve Sanat Yayınları, İstanbul, 2012.

KANIEWSKI, David, "Late second-early first millennium BC abrupt climate changes in coastal Syria and their possible significance for the history of the Eastern Mediterranean", Quaternary Research, 74, 2010, s.207-215.

KAPLUHAN, Erol, “Türkiye'de Kuraklık ve Kuraklığın Tarıma Etkisi”, Marmara Coğrafya Dergisi, S. 27, 2013, İstanbul, s. 487-510.

KUNIHHOLM, Peter, “The Archaeological Record: evidence and non-evidence for climatic change”, in: Runcorn, S.K. \& Pecker, J-C. The Earth's Climate and Variability of the Sun Over Recent Millennia. Philosophical Transactions of the Royal Society of London, 1990.

MANGALOĞLU-VOTRUBA, Sıla, “Limantepe'de Geç Hellas III C Dönemi”, Anatolia XXXVII, 2011, s. 43-73.

NAUMANN, Rudolf, Eski Anadolu Mimarlığı, TTK, Ankara, 1975.

NEUMANN J., PARPOLA, Simo, "Climatic Change and the Eleventh Century Eclipse of Assyria and Babylonia”, JNES, C.46, 3, 1987, s.161- 182.

OREN, Eliezer, The Sea Peoples and Their World, University of Pennsylvania Museum Press, 2000, s.21-24.

PALMER, Ruth, "Subsistence Rations at Pylos and Knossos", Minos, c. XXIV, 1989, s. 89- 124 .

PETROUTSA, Eirini, MANOLIS, Sotiris, "Reconstructing Late Bronze Age diet in mainland Greece using stable isotope analysis” Journal of Archaeological Science, 37, 2010, s. 614620.

REYHAN, Esma, "Hititlerde Toprak Tahsisi", III. Uluslararası Hititoloji Kongresi Bildirileri (Çorum 16-22 Eylül 1996), Ankara, 1998, s. 486-487. 
SANDARS, Nancy, The Sea Peoples: Warriors of the Ancient Mediterranean 1250-1150 B.C., Thames and Hudson, London, 1978.

SASSON, Jack, "Canaanite Maritime involvement in the Second Millennium B.C.", Journal of the American Oriental Society, 86, 1966, s. 126- 138.

SHRIMPTON, Gordon, "Regional Drought and the Economic Decline of Mycenae”, Echos du Monde Classique, c. XXXI, 1987, 137- 178.

STIEBING, William, Out of the Desert? Archaeology and the Exodus Conquest Narratives, Prometheus Books, Buffalo, 1989.

TAIZ, Lincoln, ZEİGER, Eduardo, Bitki Fizyolojisi, Palme Yayıncılı, Ankara, 2008.

TAŞ, İlknur, Hitit Kralı IV. Tudhaliya, Arkeoloji ve Sanat Yayınları, İstanbul, 2008.

UMAR, Bilge, İlkçă̆da Türkiye Tarihi, İstanbul, 1999.

ÜNAL, Ahmet, “M.Ö. II. Binyıl Anadolu'sunda Doğal Afetler”, Belleten, Sayı: 163, 1977, S.423-446.

ÜNAL, Ahmet, Anadolu'nun En Eski Yemekleri, Hititler ve Çağdaşı Toplumlarda Mutfak Kültürü, Homer Kitabevi, İstanbul, 2007.

WEISS, Barry, "The Decline of Late Bronze Age Civilization as a Possible Response to Climatic Change", Climatic Change, c. IV, 2, 1982, s.172-198.

WRIGHT, Herbert, "Climatic Change in Mycenaean Greece”, Antiquity, c. 42, sayı: 166, 1968. s.123-127.

YAMORI, Wataru, HIKOSAKA, Kouki, WAY, Danielle, "Temperature Response of Photosynthesis in $\mathrm{C}_{3}, \mathrm{C} 4$ and $\mathrm{CAM}$ plants: temperature acclimation and temperature adaption", Photosynthesis Research, 119(1-2), s. 101-117. 